There is much in heredity that has to be explained yet, and though the present pedigree does not fit in accurately with the above, it illustrates quite well the influence of heredity in lamellar cataract.

\title{
REFERENCES
}

1 and 2. Nettleship, E.-Bowman Lecture, Trans. Ophthal. Soc. of the U.K., Vol. XXIX, 1909.

\section{ATYPICAL COLOBOMA OF THE IRIS}

$$
\begin{gathered}
\text { BY } \\
\text { WAJID ALI KHAN } \\
\text { LONDON }
\end{gathered}
$$

THE following case is of interest as it proves the inflammatory origin of at least some cases of atypical colobomata of the iris.



W.F., female, aged 21 years, out-patient, Royal London Ophthalmic Hospital. The sight of the left eye has always been defective; the mother noticed something wrong with the pupil of this eye at birth. There is no history of any injury or inflammation 
of the eyes. Patient has three brothers, all have normal eyes. No history of any congenital defect in the parents.

Right eye normal, pupils active, Vc. $\frac{-3 \text { D. sph. }}{-2.5 \text { D.cyl. } 90^{\circ}}=6 / 6$.

Ophthalmoscopic examination shows a myopic fundus with wellmarked temporal crescent. There is no other abnormality present.

In the left eye vision is less than $6 / 60$, c correction $6 / 60$. There is a coloboma of the iris outwards and slightly upwards reaching to the ciliary border. It involves one-eight of the whole circumference of the iris and becomes narrower towards the ciliary margin. The sphincter muscle is not prolonged along the edges of the coloboma. Left pupil reacts to light directly and consensually, and to accommodation. With the aid of the slit-lamp thin tags of tissue resembling iris in colour (deep brown) are seen projecting forwards and inwards from the ciliary margin; they occupy the defect in the iris. They are situated at a deeper level than the iris. A white streak is seen on the anterior surface of one of them. The outer half of the lens towards the colobomatous area is cataractous and of a woolly white appearance; situated at different levels in the anterior part of the cortex at this part of the lens are dots, deep brown in colour, of various sizes and shapes. There is a slight notch in the lens posterior to the colobomatous area. There is no visible coloboma of choroid or ciliary body, but of course, this part of the fundus is difficult to see on account of lens opacities. The suspensory ligament of the lens is not visible.

The fundus shows a typical picture of congenital syphilitic choroido-retinitis. There is irregular aggregation of pigment unlike what is seen in the right eye. The optic disc in this eye is atrophic with markedly contracted vessels.

Different theories have been put forward to explain the occurrence of atypical colobomata of the iris. In the present case it is highly probable that the coloboma of the iris and the small notch in the lens are both due to some inflammatory disturbance at that particular part of the ciliary body. This also explains the cataract which is due to nutritional disturbance of the developing lens, or defective development of the suspensory ligament at that part.

My thanks are due to Sir John Parsons for allowing me to report this case, and to Miss Ida C. Mann who kindly made the drawing. 